\title{
O deôntico como manifestação do alético na psicanálise e no discurso
}

\author{
Fabio Elias Verdiani Tfouni ${ }^{\star}$ \\ Universidade Federal de Sergipe, Itabaiana, SE, Brasil
}

\begin{abstract}
Resumo
O presente trabalho tem o objetivo de tratar o interdito e o silêncio através dos aportes teóricos da psicanálise e da Análise do Discurso pêcheutiana. Essa tarefa será realizada com o uso das modalidades tanto aléticas (necessário, impossivel, possível, contingente) como deônticas (obrigatório, proibido, permitido, facultativo) da lógica aristotélica. Propomos que diversas categorias tanto psicanalíticas como discursivas podem ser tratadas através dessas modalidades. Especificamente, argumentamos que essas categorias possuem aspectos tanto aléticos como deônticos, e que o deôntico é uma manifestação local do alético. São tratadas noções e conceitos como: silêncio, censura, proibição do incesto, Lei e lei, impossível e proibido.
\end{abstract}

Palavras-chave: Psicanálise; discurso; modalidade; alético; deôntico.

\section{The deontic as a manifestation of the alethic in psicoanalysis and in discourse}

\begin{abstract}
This work consists on a treatment of interdiction and silence within the fields of Psychoanalysis and Discourse Analysis. This task will take place with a use of the Aristotelian logic both alethic (necessary, impossible, possible, contingent) and deontic (obligatory, prohibited, permited, facultative). We propose that categories like silence, interdiction, prohibition, prohibition of incest, censorship, and Law can be approached by Modal Logic. We specifically argue that these categories from Discourse analysis and Psychoanalysis have alethical and deontical aspects, and that the deontic is a manifestation of the aletic.
\end{abstract}

Keywords: Psychoanalysis; discourse; modality; alethic; deontic.

\section{Introdução}

Em trabalhos anteriores temos afirmado que o interdito é fundador do discurso (TFOUNI, F., 1998, 2006, 2008, 2010). Essa hipótese aponta para o fato de existir um impossível na linguagem que é constitutivo e fundador. Se existisse um enunciado que fosse completo no sentido de dizer tudo, então, após tal enunciação não haveria mais o que dizer e o campo da enunciação fechar-se-ia. Isso seria a morte da linguagem. Assim, a linguagem precisa ser incompleta e faltante para que se possa dizer alguma coisa. Justamente porque existe uma falta na linguagem, é que se pode continuar dizendo, pois, a completude não chega nunca. Nesse sentido tomamos aqui a tese lacaniana trabalhada também por Milner (1987) que afirma que "tudo não se diz".

Como o sistema da língua é marcado por um furo do real no simbólico, e, visto que este último não recobre totalmente aquele, haveria ao menos um elemento do simbólico fora do sistema. Então, podemos dizer que o interdito, o silêncio e o impossível são necessários para a estrutura, que aqui não corresponde à estrutura fechada de Saussure. Ela antes comporta uma falta, ou seja: trata-se de algo incompleto. Por isso a análise do discurso tem preferido falar em sistematicidade, mais do que em sistema. Sobre as formas do silêncio, Orlandi (1995, p. 24) afirma:

Por isso distinguimos entre a) o silêncio fundador, aquele que existe nas palavras, que significa o não dito e que dá espaço de recuo significante, produzindo as condições para significar e b) a política do silêncio que se subdivide em b1) silêncio constitutivo, o que nos indica que para

\footnotetext{
^Endereço para correspondência: Universidade Federal de Sergipe, Campus Prof. Alberto Carvalho. Av. Vereador Olímio Grande, s/n - Centro. CEP: 49500-000 - Itabaiana, SE - Brasil.E-mail: fabiotfouni@hotmail.com
}

dizer é preciso não dizer (uma palavra apaga necessariamente as outras palavras) e b2) o silêncio local, que se refere à censura propriamente (aquilo que é proibido dizer em uma certa conjuntura).

A censura impede a circulação dos sentidos localmente. Como afirma Orlandi, a censura é a proibição do formulável. Essa proibição local seria a forma fraca do interdito. No entanto, a própria autora aponta para um outro tipo de proibição do dizer, que não caracterizamos como proibição, mas como delineada pelo impossível. Há uma parte do campo dos sentidos que nunca dizemos e, que não chegamos nem mesmo a formular ou a reconhecer. Este seria um interdito estrutural. O impossível de dizer, enquanto necessidade estrutural da linguagem deve ser universal, deve estar em toda estrutura de linguagem e em toda enunciação.

Já o interdito é o agente que corta limitando e separando o que pode do que não pode ser dito. Comentamos anteriormente como ele possui valor estrutural. Pois bem: a censura - o ato de censurar - é uma manifestação local da necessidade estrutural de uma interdição na linguagem. De modo geral, toda estrutura comporta um impossível. O proibido é uma manifestação local do impossível. Mais adiante vamos trabalhar detalhadamente essa questão.

O objetivo específico deste trabalho é o de argumentar que existe um não-dito estrutural e não ditos locais como a censura, que os não ditos locais são manifestações culturais de um impossível estrutural e que o proibido é a manifestação cultural do impossível. Também fazemos a hipótese de que tudo isso pode ser interpretado através das modalidades da lógica aristotélica. Vamos usar aqui a ló- 
gica alética e a lógica deôntica. Nossa hipótese é a de que os não ditos locais e as proibições locais são manifestações deônticas de um impossível (e de um impossível de dizer).

\section{Desenvolvimento}

Nesta seção vamos recorrer à lógica para tratar a questão do deôntico como manifestação do alético, bem como as consequências dessa questão lógica para questões da psicanálise e do discurso, especificamente no que se refere ao interdito e ao silêncio, passando pela questão da interdição do incesto e da Lei.

Apresentamos abaixo o quadrado das oposições, com seus cantos ou vértices e as relações entre eles:

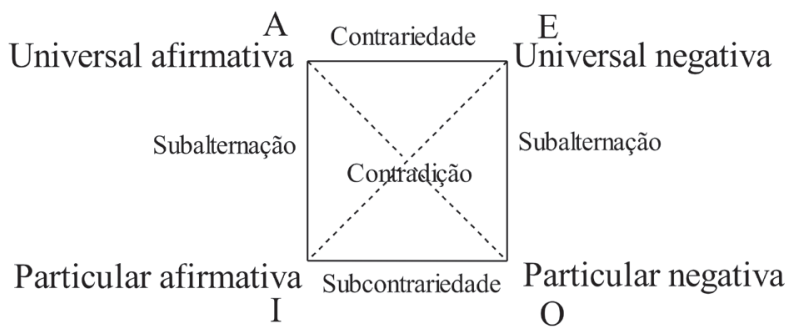

Vamos explicitar agora os fundamentos necessários para o nosso tratamento da linguagem no quadrado. Nele são colocadas proposições categóricas. Segundo Copi (1978), as proposições categóricas têm uma qualidade e uma quantidade. $\mathrm{O}$ autor prossegue afirmando que "A qualidade de uma proposição é afirmativa ou negativa [...] segundo a inclusão de classe for afirmada ou negada pela proposição" (COPI, 1978, p. 143). Então, as proposições universais afirmativas e particulares afirmativas são afirmativas em qualidade. As do outro lado - as negativas - são negativas em qualidade.

Sobre a quantidade, Copi (1978, p. 143) afirma que: "A quantidade de uma proposição é universal ou particular segundo a proposição se refira a todos os membros ou só a alguns dos membros da classe designada pelo seu termo sujeito". Dessa forma, as proposições dos cantos A e E são universais e as dos cantos I e O são particulares.

O quadrado das oposições não é apenas uma figura geométrica, mas é uma figura na qual os cantos possuem certas relações lógicas, de modo que as relações entre as proposições - que são relações de oposição - são determinadas pelas posições que estas ocupam no quadrado. Sobre isso, afirma Copi (1978, p. 146):

As proposições categóricas de forma típica que têm os mesmos termos sujeito e predicado podem diferir mutuamente na qualidade ou na quantidade ou em ambas as coisas. Os lógicos de outrora deram a essa espécie de diferença o nome técnico de 'oposição' e certas relações importantes dos valores de verdade foram correlacionadas com várias espécies de oposição.

Resumidamente podemos dizer que a relação de subalternação significa que, se a proposição do canto A é verdadeira, então sua subalterna, a do canto I, também recebe valor de verdade $\mathrm{V}$. O mesmo vale para os cantos $\mathrm{E}$ e O.
Os predicados aléticos formam o quarteto modal aristotélico, sendo eles, o impossível, o possível, o contingente e o necessário. "As proposições aleticamente necessárias são também verdadeiras e necessárias em todos os mundos possíveis" (TFOUNI, L., 1986, p. 122). Assim, temos o quadrado abaixo, que encontramos em Darrault (1976); Costa, (1986) e em Greimas, (1976):

\section{Necessário}

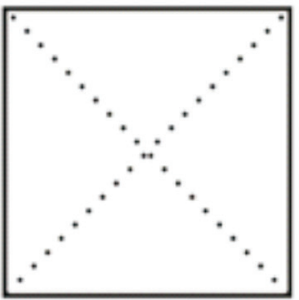

\section{Possivel}

Impossivel

Recorrendo à lógica modal, podemos formalizar a questão aqui pesquisada da seguinte maneira: há um silenciamento alético, que é estrutural, que resulta de um interdito também alético, que se caracteriza por um impedimento radical, ou seja, ao dizer constitutivamente impossível. E há um silêncio que corresponde a uma proibição local, sendo este um silêncio deôntico, relacionado ao que é certo ou errado culturalmente. O proibido seria uma manifestação cultural do estruturalmente impossível. Deste modo, evidencia-se um retorno das modalidades lógicas, o que corrobora a importância destas num tratamento da linguagem.

É nesse sentido que podemos afirmar que o impossível é fundador do discurso, pois, o impossível é um estruturante válido para todas as estruturas, inclusive a linguagem. Portanto, a estrutura tem regras internas válidas para todos os mundos possíveis.

Isso não se limita ao discurso. Lévi-Strauss chegou a propor que a estruturação das sociedades era produto do impossível do incesto. Essa proibição existiria em todas as sociedades incluindo a nossa e também as primitivas, tendo o caráter universal de um impossível alético.

No entanto essas proibições universais ganham contornos imaginários em cada cultura; assim, a proibição do incesto é universal, mas a maneira como ela será regulada, é cultural, e, portanto, particular a cada grupo. Esse tipo de impedimento ou silenciamento (no caso da linguagem) seria caracterizado pela modalidade deôntica, na medida em que a modalidade

[...] deôntica está relacionada com a necessidade ou possibilidade de atos realizados por agentes moralmente responsáveis. Sendo assim, a modalidade deôntica abrange uma escala que inclui a obrigação, a permissão a proibição e a isenção. Algumas lexicalizações desta modalidade são: 'certo', 'errado', 'ilegal', 'impróprio', 'imoral', 'injusto' etc. (TFOUNI, L. 1986, p. 125).

O quadrado abaixo, que denominaremos "quadrado deôntico", formaliza as relações entre as modalidades deônticas. Este quadrado pode ser visto em Darrault, (1976); e em Greimas, (1976). 


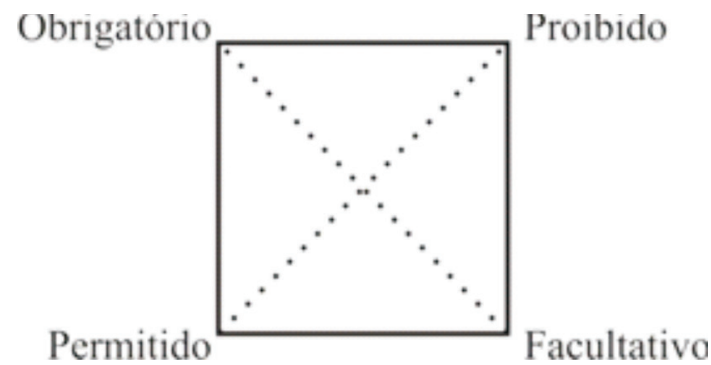

Seria interessante apresentar ao leitor de forma mais aprofundada as noções de alético e de deôntico, bem como as diferenças entre a lógica tradicional e a lógica modal, no entanto, em um trabalho como este, cuja finalidade é verificar a aplicabilidade desses construtos na psicanálise e na análise do discurso, fazer isso seria mudar o foco para uma revisão teórica. No entanto, a fim de situar melhor a questão das modalidades deôntica e alética, ao longo do texto estamos apresentando os esclarecimentos necessários para uma leitura adequada.

Convém ao menos apresentar uma dificuldade lógica das teses aqui apresentadas: Se as verdades aléticas são verdades em todos os mundos possíveis, então o necessário se aplica "automaticamente"; não existe dúvida ou hesitação. Já a lógica deôntica, por ser do domínio da moral, não funciona assim. No deôntico (na moral) existem dúvidas sobre a melhor forma de agir, de modo que a lógica deôntica (ou a verdade deôntica) não funciona do mesmo modo que a alética. Por exemplo, se digo que é uma verdade alética que "massa atrai massa" (a lei da gravidade), isso se aplica imediatamente a todo corpo que possui massa. No campo da moral isso não funciona assim. Por exemplo, é moral (ou não) o aborto? É moral o uso de embriões congelados (vida?) para experiências no campo da genética? Uma das possibilidades seria a de considerar não todos, mas apenas certos traços fundadores da existência humana, da sociedade e do discurso, como passiveis de uma leitura que considere o deôntico como manifestação do alético. Como seria o caso da proibição do incesto, que se "irraidia" para a psicanálise e para o discurso tendo consequências para o sujeito e para o que se pode (ou não) dizer.

É o que acontece com as línguas: todas contêm o agramatical, o indizível o impossível de ser dito; no entanto, o preenchimento imaginário desse impossível acaba particularizado por cada grupo lingüístico. Diríamos que a existência da linguagem se funda por uma ordem interna universal, que requer um não-dito ou um silêncio.

Percebemos que é possível fazer uma leitura alética e deôntica do silêncio como tratado por nós (TFOUNI, F., 2008, 2010) e por Orlandi (1995). O silêncio local, a censura, o proibido de dizer, são proibições no nível do formulável, de modo que o silêncio constitutivo e o silêncio fundador tem que estar sempre presentes, e são, portanto, aléticos.

A figura abaixo consiste numa projeção do quadrado deôntico sobre o alético apresenta nosso tratamento lógico da hipótese de que o deôntico é uma manifestação do alético:

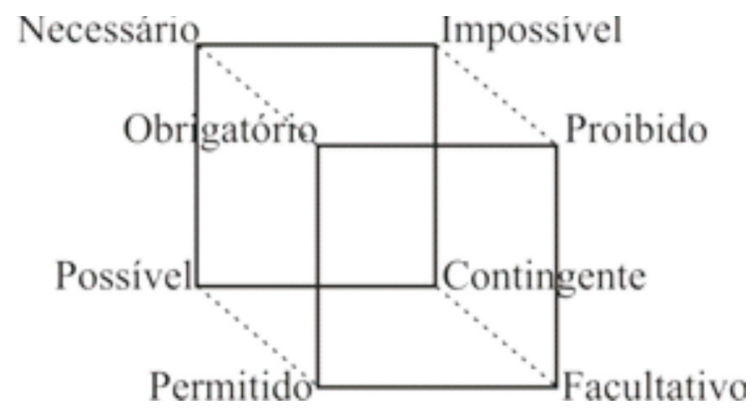

Continuando nossa discussão, lembramos que em nosso trabalho temos tentado diferenciar o interdito do proibido. O interdito seria o que é estruturalmente impossível. Já o proibido, seria aquilo que é possível, mas impedido.

Se as modalidades se relacionam com leis no sentido do obrigatório, do proibido, do permitido e do facultativo, cabe perguntar: De onde viriam essas leis?

Como já dissemos anteriormente, a lei da proibição do incesto é uma manifestação local de um impossível: o impossível do incesto. Então o impossível se faz presente na sociedade humana a partir do proibido. É assim que lemos o seguinte trecho de Magno Dias (1986, p. 16): “' “O incesto é o impossível, por isso é que ele é proibido, já falei zil vezes”.

Avançando um pouco, diremos que a Lei se confunde com o simbólico por ser introduzida pela própria entrada da linguagem no homem através da metáfora paterna. A metáfora paterna é a operação que realiza a captura do sujeito pela linguagem, submetendo-o à Lei do Falo. Na fórmula abaixo, podemos ver que o desejo da mãe é substituído pelo nome do pai que, por sua vez, introduz a Lei no sujeito.

$$
\frac{\text { Nome-do-Pai }}{\text { Desejo da Mãe }} \cdot \frac{\text { Desejo da Mãe }}{\text { Significado para o sujeito }} \rightarrow \text { Nome-do-Pai }\left(\frac{\mathrm{A}}{\text { Falo }}\right)
$$

(Extraído de LACAN, 1998, p. 563)

A metáfora paterna é uma operação que reproduz no nível individual um impedimento mais amplo, a proibição do incesto. Para que a sociedade exista, é necessária a proibição do incesto que na verdade seria uma manifestação cultural do impossível do incesto. A proibição do incesto é universal. Por isso afirmamos que o impossível do incesto é um impossível alético, no sentido de que é um impossível válido para todas as sociedades (para todos os mundos possíveis).

Para abordar a questão do universal e do particular no homem - questão que, para nós, em termos lógicos se refere ao alético e ao deôntico -, Joël Dor recorre aos escritos de Lévi-Strauss. Para compreender o homem numa perspectiva antropológica devemos buscar o que é universal ao homem, buscar algo que todos tenhamos. Por ser universal, esse $\mathrm{X}$ pode ser considerado aquilo de que o homem é feito e que o distingue do não-homem. É assim que leio o trecho abaixo de Dor (1991, p. 25):

${ }^{1}$ Trazemos autores como Magno, Dor e Lacan que podem não convergir (ou mesmo divergir) em certas questões, na medida em que esses autores fornecem alguns subsídios para pensarmos as teses levantadas neste trabalho. 
Por um lado, o natural deve poder, por definição, obedecer a leis universais. Por outro, o cultural, este parece só pode ser instituído a partir de regras particulares de funcionamento. Portanto tudo que houver de universal no homem constituirá sua natureza. Devendo todo o resto, necessariamente, ser considerado como um produto da cultura.

Vemos acima Dor tratando do universal no homem (sua natureza), que seria aquilo que está presente em todas as sociedades. Em termos lógicos, lemos essa faceta do humano como seu aspecto alético. Ao mesmo tempo o resto (não universal) seria relativo à cultura. Nossa posição é a de que esse resto é relativo à modalidade deôntica.

Sobre a proibição do incesto, Dor (1991) traz Lévi-Strauss, argumentando que a proibição do incesto não é puramente de origem natural nem totalmente de origem cultural.

Num sentido ela pertence à natureza, pois é uma condição geral da cultura, e consequentemente não devemos nos surpreender de vê-la manter da natureza o seu caráter formal, isto é, a universalidade. Mas, num sentido, também, ela já é a cultura, agindo e impondo sua regra no seio de fenômenos que em nada dependem originalmente dela (Lévi-Strauss apud Dor, 1991, p. 27).

Lemos o trecho acima também como relativo às modalidades alética e deôntica, porém nesse trecho percebemos que aquilo que é universal é a proibição do incesto. Aspecto então, modalizado aleticamente. Dor fala também da manifestação dessa proibição (desse impossível) na cultura. Nossa leitura é a de que a maneira como essa proibição se manifesta é modalizada deonticamente.

Dor (1991) prossegue mostrando como o Édipo está ligado à passagem da natureza à cultura, e diz que a teoria psicanalítica se aproxima da antropologia, ao recolocar a existência de uma natureza no homem. Isto se dá através de um substrato psicológico que se manifesta na ordem edípica. Dor (1991, p. 29) afirma:

O homem, com efeito, participa da natureza por sua inscrição incontornável na dinâmica edipiana que é fundamentalmente ordenada pela dialética do desejo em face da diferença dos sexos. Em outras palavras, é porque a lei da proibição do incesto é capaz de estabelecer o limite entre o natural e o cultural que a ordem edípica pode, legitimamente, apresentar-se como o substrato universal que designa a dimensão do natural no homem.

A ordem edípica aparece como o natural no homem por ser incontornável, e, nesse sentido, universal. A comparação com a proibição do incesto em Lévi-Strauss faz-se importante aqui no sentido em que a ordem edípica é natural e, ao mesmo tempo, cultural, pois é através dela que se acede ao simbólico. Então, por ser uma regra universal a proibição do incesto - e também a ordem edípica -, temos algo que é da ordem do alético, por ser válida em todos os mundos possíveis, sendo universal Comenta Dor (1991, p. 29):

[...] tornando-se coextensiva à ordem edípica, a problemática natureza-cultura desloca seu espaço de oposição insolúvel para o de um conflito passível de uma saída. De fato, a ordem edípica se define como o lugar de tal con- flito, suscetível de acabar permitindo ao sujeito aceder ao registro do simbólico, ou seja, à cultura.

A proibição do incesto é um proibido local que funciona como elemento interditor, elemento que proíbe e ao mesmo tempo funda o possível, pois é a operação que funda o desejo. Alguns pensadores costumam opor a lei ao desejo, de modo que a lei seria o que impede o desejo, mas a Lei e o desejo formam um binômio. Como diz Magno (DIAS, 1986, p. 8), "A lei é desejo"

Assim, é importante perceber que a Lei, ao contrário de ser o que impede o desejo, ela é o que o funda. Essa operação, sendo também a operação de entrada da linguagem pode ser vista como fundadora do discurso. A impossibilidade da criança em significar o "tudo" do desejo da mãe, vai permitir que se abra o campo da enunciação, justamente pela retirada da completude. Então, o interdito a dizer tudo é justamente o que permite que se diga alguma coisa. É porque há Lei que algo não é dizível, para que o resto o seja.

Talvez seja possível pensar que, no universo discursivo, a existência de algo, de pelo menos um elemento fora do universo discursivo possa ser o que permite conceber o universo discursivo. Dizendo de outro modo. Os significantes faltam, e essa falta é estrutural. Ao invés de ser uma falta negativa, trata-se de uma falta fundadora e estruturante. Talvez o trecho seguinte de Leite (1994, p. 92) se refira a isso:

O tema do interdito se refere aqui à imposição, consequente da própria estrutura da linguagem, do fato de não se poder abarcar todos os significantes ao mesmo tempo. A relação específica que vige entre linguagem-inconsciente-castração tem como implicação que não se pode dispor do conjunto dos significantes.

Magno comenta no seguinte parágrafo a diferença entre Lei e lei, e aborda outros aspectos importantes para o nosso trabalho, como o fato de a Lei ser o universal do homem e o simbólico, borda de um real impossível de ser dito, e, portanto, na linha de nosso trabalho, interditado

Estamos falando da Lei com L maiúsculo. Se supôs a possibilidade do universal por remissão a ela, ela pode ser o universal, e eu posso dizer "A Lei”. A Lei não são as leis, os regulamentos, exarados no seio da cultura e designadores dos conjuntos, ou melhor, de determinados grupos de falantes. A Lei a que estamos querendo nos referir é essa borda do real quando se pode dizer que a relação sexual é impossível, que o Real é impossível, o impossível de ser inscrito (DIAS, 1991, p. 09).

A abordagem que temos feito nos leva a ler o trecho acima de Magno (DIAS, 1991) como tratando de uma Lei (com "L" maiúsculo) universal. Para nós, ela seria modalizada aleticamente. Ao mesmo tempo, Magno trata das leis (com "l" minúsculo), leis no seio da cultura, que temos tratado até aqui como deônticas.

Talvez, no âmbito da cultura, possamos dizer também que temos uma proibição num nível superegóico: a lei se dá apoiada num saber, numa consciência. Saber fica aqui relacionado ao sujeito ter consciência, conhecimento. Esta seria uma proibição local, para nós, deôntico, uma lei que 
se enuncia que se escreve nos códigos culturais. Por isso, nossa hipótese é a de que se trata aqui de uma lei com 1 minúsculo, uma lei deôntica que seria a manifestação local de uma Lei maior, de um impossível. Já o simbólico, essa outra Lei, o impossível, não se baseiam num saber. Para que haja simbólico, basta haver uma Lei, que é inconsciente.

Nossas colocações sobre o alético e o deôntico, o impossível e o proibido (tanto no dizer como na questão do incesto), bem como sobre a Lei e a lei podem ser vistas na tabela abaixo (tabela 1 ), na qual a coluna B seria uma manifestação da coluna $\mathrm{A}$ :

\begin{tabular}{|c|c|} 
Tabela 1 \\
\begin{tabular}{|c|c|}
\hline A & B \\
\hline Alético & Deôntico \\
\hline Impossível & Proibido \\
\hline Impossível de dizer & Proibido de dizer (Censurado) \\
\hline Impossível do incesto & Proibição do incesto \\
\hline Lei & Lei \\
\hline
\end{tabular}
\end{tabular}

\section{Análises}

O conjunto de interlocutores de uma pessoa, numa sociedade primitiva, tem relações com a proibição do incesto. Assim, um homem não poderá falar com sua irmã, por exemplo. Nem sempre a comunicação é proibida; às vezes ela é possível, com a observação de certos rituais.

Isso provavelmente está ligado ao fato de que o incesto é impossível - a proibição é a manifestação cultural do impossível. O sexo, justamente por ser um ponto onde há um impossível, é recheado de proibições (MILNER, 1987).

Tomando essa afirmação de Milner, vamos tratar aqui de certas regras apontadas por Freud relativas à proibição do incesto em povos primitivos. Vamos listar exemplos em que haja um proibido de dizer relacionado à proibição do incesto. Os exemplos são retirados por Freud de outros pensadores. Esses exemplos fazem parte das chamadas “evitações” (cf. FREUD, 1995[1913], p. 29).

Nossa leitura é a de que os exemplos de Freud apontam para o universal da proibição do incesto. Ao mesmo tempo, os exemplos mostram que esse impossível se manifesta em proibições das mais diversas, nas várias sociedades. As proibições (ou evitações) $\mathrm{X}$ ou Y são manifestações culturais (e, por isso, imaginárias em parte) do impossível do incesto. Esses exemplos são interessantes porque a um só tempo, trazem "evitações" relativo à proibição do incesto e ao mesmo tempo a uma proibição no campo do dizer.

O objetivo está mais em apontar que existe um tipo de proibição ao dizer ligado à proibição do incesto e não em fazer relato exaustivo dessas proibições e evitações. Assim, repetimos Freud (1995[1913], p. 31): "Desde que estamos menos interessados na extensão etnográfica dessa evitação do que em sua substância e objetivo, mais uma vez vou restringir-me a citar alguns exemplos".

Freud aponta que em alguns casos, a irmã não pode conversar com o irmão ou pronunciar o nome dele. Eis Freud (1995[1913], p. 29, grifo nosso): "Entre os nativos da península Gazelle, na Nova Bretanha, não é permitido que uma moça, depois de casada, converse com o irmão; ela nunca pronuncia o nome dele; designa-o por outra palavra".

Isso organiza a sociedade, já que a interlocução é regulada, e por isso funciona como um sistema, onde um homem de uma família não pode ter todos os interlocutores, e só por isso pode ter algum.

Sobre um povo da Melanésia, Freud (1995[1913], p. 29, grifo nosso) afirma: "Se um menino souber que certas pegadas na estrada são de sua irmã, não as seguirá, como ela também não seguirá as dele. Na realidade nem sequer pronuncia o nome dela e uma palavra comum, se fizer parte desse nome".

E ainda sobre esse povo:

A reserva entre filho e mãe aumenta à medida que o menino cresce, sendo muito maior da parte dela do que da dele. Se a mãe lhe traz comida, não a entrega diretamente, coloca-a no chão para que ele a apanhe. No diálogo não o trata por tu, usa as formas mais cerimoniosas do plural (FREUD, 1995[1913], p. 29, grifo nosso).

Sobre os habitantes de Vaua Lava, em Port Patteson, Freud (1995[1913], p. 31, grifo nosso) diz: "Não obstante, o genro e a sogra podem falar-se a uma certa distância, mas uma mulher em nenhuma circunstância menciona $\mathrm{O}$ nome do marido de sua filha, nem ele o dela".

\section{Considerações finais}

O presente trabalho argumentou que aquilo que é universal no homem pode ser tratado como alético, já que é válido para todos os mundos possíveis. Essa modalização alética é relativa à linguagem e à Lei, uma Lei com L maiúsculo. Essa Lei universal é a proibição do incesto. Podemos dizer que a proibição do incesto, no nível individual se manifesta na metáfora paterna - ela mesma introdutora da Lei no homem.

No reino do discurso, quanto ao dizer e à enunciação este trabalho permite afirmar que existe um não-dito, um silêncio que é estrutural, ou seja: deve estar necessariamente presente onde haja enunciação, o que significa que existe um impossível de dizer sob a forma de uma Lei alética que se manifesta na cultura, e essa manifestação se dá no nível do proibido e da censura.

A Lei é a própria linguagem, é a entrada de um significante designado nome-do-pai, que impede o tudo dizer. Então, estar na Lei significa que não é possível dizer tudo. Lei e linguagem são uma coisa só visto que é um significante que introduz a Lei, e por isso, a cultura é linguagem.

Como existe uma Lei alética relativa ao impossível de se dizer tudo, isso precisa se manifestar na cultura, e essa manifestação se dá no nível do proibido, do proibido de dizer e da censura.

Trouxemos alguns exemplos da literatura psicanalítica que tratam de proibições (as evitações de Freud), as quais, em nossa leitura, são a manifestação cultural de um impossível, o impossível do incesto pois, para nós, a proibição do incesto é, na verdade, o impossível do incesto. Isso tem relação com "o que se pode falar e com quem 
se pode falar" nas sociedades cujos exemplos foram extraídos. Ou seja: existe uma relação entre a proibição do incesto e os silenciamentos presentes nas evitações.

O impossível do incesto é regulado na cultura por proibições. A proibição $\mathrm{A}, \mathrm{B}$, ou $\mathrm{C}$ são manifestações desses impossíveis. Nesse sentido, o proibido de dizer e a proibição do incesto são manifestações que mesclam aspectos imaginários e simbólicos. Poderíamos supor que o proibido seria apenas do imaginário, mas, na medida em que ele é uma manifestação do simbólico da Lei, deve estar presente aí também.

\section{Referências}

COPI, I. M. Introdução à lógica. São Paulo: Mestre Jou, 1978.

COSTA, N da. Entrevista. Isso - dispensa freudiana, Belo Horizonte, n. 1, p. 32-33, 1986.

DARRAULT, I. Présentation. Langages, n. 43, p. 3-9, 1976.

DOR, J. O Pai e sua função em psicanálise. Rio de Janeiro: J. Zahar, 1991.

FREUD, S. Totem e Tabu (1913). In: SALOMÃO, J. (Org.). Obras Psicológicas Completas de Sigmund Freud. Tradução de Órizon Carneiro Muniz. Rio de Janeiro: Imago. 1995. v. XIII, p. 21-163, Edição Standard Brasileira.

GREIMAS, A. J. Pour une théorie des modalités. Langages, n. 43, p. 47-63, 1976.

LEITE, N. Psicanálise e análise do discurso: o acontecimento na estrutura. Rio de Janeiro: Campo Matêmico, 1994.

DIAS, M. M. Psicanálise e Polética. Rio de Janeiro: Aoutra, 1986.

LACAN, J. Escritos. Rio de Janeiro: J. Zahar, 1998.

MILNER, J.-C. O amor da língua. Tradução de Ângela Cristina Jesuino. Porto Alegre: Artes Médicas. 1987.

ORLANDI, E. P. As formas do silêncio: no movimento dos sentidos. 3. ed. Campinas: Unicamp, 1995.

TFOUNI, F. E. V. O interdito como fundador do discurso. 1998. Dissertação (Mestrado)-Instituto de Estudos da Linguagem, Universidade Estadual de Campinas, Campinas, 1998.

TFOUNI, F. E. V. O interdito como fundador do discurso. Letras \& Letras, Uberlândia, v. 22, n. 1, p. 127-137, jan./jun. 2006.

TFOUNI, F. E. V. O interdito e o silêncio: duas abordagens do impossível na linguagem. Linguagem em (Dis)curso, Tubarão, v. 8, n. 2, p. 353-371, maio/ago. 2008.

TFOUNI, F. E. V. Interdito e silêncio: uma abordagem no quadrado das oposições. Signótica, Goiânia, v. 22, n. 2, p. 343 $355,2010$.

TFOUNI, L. V. Adultos não-alfabetizados: o avesso do avesso. 1986. Tese (Doutorado em Linguística)-Instituto de Estudos da Linguagem, Universidade Estadual de Campinas, Campinas, 1986.

Recebido em: 10 de outubro de 2012

Aceito em: 25 de setembro de 2015 